\title{
Pyramidal Cells of the Frontal Lobe: All the More Spinous to Think With
}

\author{
Guy N. Elston \\ Vision, Touch and Hearing Research Centre, Department of Physiology and Pharmacology, The University of Queensland, \\ Queensland, 4072 Australia
}

The basal dendritic arbors of pyramidal cells in prefrontal areas 10,11 , and 12 of the macaque monkey were revealed by intracellular injection in fixed, flat-mounted, cortical slices. The size, number of branches, and spine density of the basal dendrites were quantified and compared with those of pyramidal cells in the occipital, parietal, and temporal lobes. These analyses revealed that cells in the frontal lobe were significantly more spinous than those in the other lobes, having as many as 16 times more spines than cells in the primary visual area (V1), four times more those in area $7 \mathrm{a}$, and $45 \%$ more than those in area TE. As each dendritic spine receives at least one excitatory input, the large number of spines reported for layer III cells in prefrontal cortex suggests that they are capable of integrating a greater number of excitatory inputs than layer III pyramidal cells so far studied in the occipital, parietal, and temporal lobes. The ability to integrate a large number of excitatory inputs may be important for the sustained tonic activity characteristic of neurons in prefrontal cortex and their role in memory and cognition.

Key words: intracellular injection; Lucifer yellow; striate; extrastriate; dendritic spine; cable; association; population coding; binding
Recent studies have revealed significant and systematic differences in the size, number of bifurcations, and spine density of the basal dendritic arbors of pyramidal cells in sensory cortical areas of the occipital, parietal, and temporal lobes of monkeys (Elston and Rosa, 1997, 1998a; Elston et al., 1999a,b). Moreover, these studies have revealed systematic differences in the number of spines in the basal dendritic arbors of pyramidal cells in different cortical areas. As each dendritic spine receives at least one synapse (for review, see DeFelipe and Fariñas, 1992; Horner, 1993), these findings suggest that pyramidal cells in different cortical areas are capable of integrating different numbers of inputs and that cells in visual association areas are capable of integrating more inputs than those in "lower" visual areas.

Prefrontal cortex, unlike sensory cortex, is involved in higher functions such as memory, comprehension, and thought (GoldmanRakic, 1996; Courtney et al., 1998). Furthermore, neurons in prefrontal cortex differ from those in sensory cortex in that they are characterized by sustained tonic activity (Fuster and Alexander, 1971; Kubota and Niki, 1971; Fuster, 1973; Funahashi et al., 1989). Does it follow, then, that pyramidal cells in prefrontal cortex have morphologies that differ from those in other lobes? Presently available data from Golgi studies suggest that those in areas 9 and 46 are no larger than those in the fourth visual area and that they are not particularly spinous (Lund et al., 1993; Anderson et al., 1995). The present study focused on the morphology of intracellularly injected pyramidal cells in cytoarchitectonic areas 10, 11, and 12 of the macaque monkey. The results show that cells in these areas are considerably more spinous than those in visual and visual association cortical areas.

Received May 5, 2000; revised June 19, 2000; accepted June 26, 2000.

This work was supported by a project grant (971113) and a CJ Martin Fellowship from the Australian National Health and Medical Research Council. I thank Dr. Rosa for continued support, Dr. Vaney for generously allowing me access to his cell injection laboratory, Dr. DeFelipe for letting me use his facilities to analyze the data, Dr. Pow for providing his antibody to Lucifer yellow, Dr. Calford and Dr. Brinkman for providing the tissue, and R. Tweedale for technical help.

Correspondence should be addressed to Guy Elston, Vision, Touch and Hearing Research Centre, Department of Physiology and Pharmacology, The University of Queensland, QLD 4072, Australia. E-mail: G.Elston@vthrc.uq.edu.au.

Copyright (C) 2000 Society for Neuroscience $0270-6474 / 00 / 200001-04 \$ 15.00 / 0$

\section{MATERIALS AND METHODS}

Intracellular injection and immunohistochemistry. Methods of perfusion, slice preparation, cell injection, classification, and morphological and statistical analysis have been detailed in previous studies (Elston et al., 1996; Elston and Rosa, 1997, 1998a). Briefly, tissue for cell injection was obtained from the medial wall of the frontal pole, inferior and adjacent to the rostral extent of the cingulate sulcus (area 10), from the lateral orbital gyrus adjacent to the fronto-orbital sulcus (area 11), and from the inferofrontal gyrus, adjacent to the fronto-orbital sulcus (area $12_{\text {orbital }}$ ) of the left hemisphere of a 12 -year-old female macaque monkey. Nomenclature of frontal areas is that of Preuss and Goldman-Rakic (1991a).

Cortex was prepared as flattened preparations by "unfolding" the sulci, removing the white matter, and post-fixing between glass slides. Sections ( $250 \mu \mathrm{m}$, tangential to the cortical surface) were cut with the aid of a vibratome and prelabeled with the fluorescent dye 4,6 diamidino-2phenylindole (DAPI; Sigma D9542), allowing visually guided injection. Cells were injected with Lucifer yellow (8\% in $0.1 \mathrm{M}$ Tris buffer, $\mathrm{pH} 7.4$ ) by hyperpolarizing continuous current. After injection of neurons, the tissue was processed for an antibody to Lucifer yellow, biotinylated, and reacted for 3,3'-diaminobenzidine (DAB) reaction product (Fig. 1).

Data analyses. Cells were drawn with the aid of a camera lucida, and dendritic field areas were calculated by determining the area contained within a polygon joining the outermost distal tips of the dendrites. Branching patterns were determined by Sholl analyses (Sholl, 1953), by counting the number of dendritic intersections with concentric circles centered on the cell body with increasing radii of $25 \mu \mathrm{m}$. Spine densities were plotted by counting the number of spines per $10 \mu \mathrm{m}$ of 20 horizontally projecting dendrites of different cells in each cortical area. These features were quantified and compared statistically using GB Stat (Dynamic Microsystems, Silver Spring, MD) or Statview (Abacus concepts, Berkeley, CA). By combining data on the average number of dendritic bifurcations, as a function of distance from the cell body, with average

This article is published in The Journal of Neuroscience, Rapid Communications Section, which publishes brief, peerreviewed papers online, not in print. Rapid Communications are posted online approximately one month earlier than they would appear if printed. They are listed in the Table of Contents of the next open issue of JNeurosci. Cite this article as: JNeurosci, 2000, 20:RC95 (1-4). The publication date is the date of posting online at www.jneurosci.org.

http://www.jneurosci.org/cgi/content/full/4498 

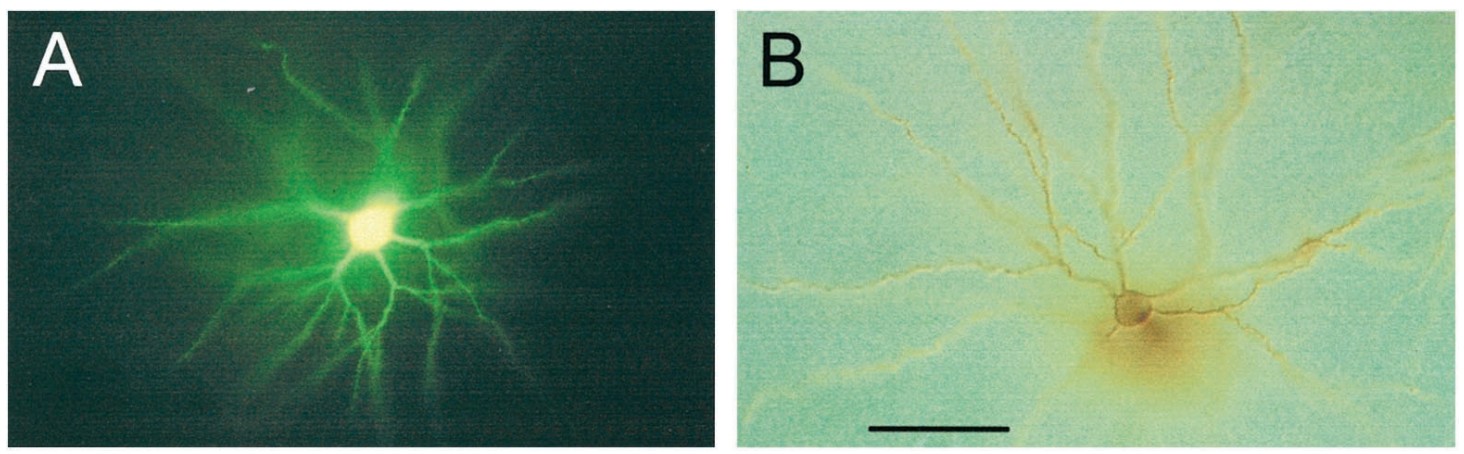

Figure 1. Photomicrographs of layer III cortical pyramidal neurons injected with Lucifer yellow $(A)$ and processed for a DAB reaction product $(B)$. Scale bar, $100 \mu \mathrm{m}$.

spine densities, the total number of spines in the basal dendritic field was determined for the "average" neuron in each area. Data for V1, 7a, and TE have been published previously (Elston and Rosa, 1997, 1998a; Elston et al., 1999a).

\section{RESULTS}

A total of 313 neurons were included for analysis as they had an unambiguous apical dendrite and basal dendritic tree characteristic of pyramidal neurons (for review, see DeFelipe and Fariñas, 1992), and their cell bodies were located in layer III.

\section{Basal dendritic field areas}

The basal dendritic field areas of layer III pyramidal neurons in areas 10,11 , and 12 were significantly larger than those in cortical areas in the occipital, parietal, and temporal lobes such as V1 $(n=136), 7 \mathrm{a}(n=40)$ and TE $(n=50)(p<0.01$ in all cases $)$ (Fig. $2 A)$. Moreover, those in area $10(n=29$; mean $\pm \mathrm{SD}$, $\left.133.2 \times 10^{3} \pm 3.70 \times 10^{3} \mu \mathrm{m}^{2}\right)$ were statistically larger than those in areas $11\left(n=37\right.$; mean $\pm \mathrm{SD}, 123.7 \times 10^{3} \pm 4.64 \times 10^{3}$ $\left.\mu \mathrm{m}^{2}\right)$ and $12\left(n=21\right.$; mean $\pm \mathrm{SD}, 126.8 \times 10^{3} \pm 5.58 \times 10^{3}$ $\mu \mathrm{m}^{2}$ ). Frequency distributions revealed that there was a greater degree of variation in the size of the basal dendritic trees in areas 11 and 12, as compared with area 10. Moreover, there was a bimodal and trimodal distribution in the basal dendritic field areas in cortical areas 11 and 12, respectively (Fig. 2A).

\section{Complexity of the basal dendritic fields}

Branching patterns of the basal dendritic fields of layer III pyramidal neurons are shown in Figure $2 B$. The basal dendritic trees of cells in areas 10,11, and 12 characteristically had many branches. The maximum number of dendritic branches in all three prefrontal cortical areas was found at a distance of $75 \mu \mathrm{m}$ from the cell body and ranged from $32.35 \pm 4.41$ in area 10 to $33.51 \pm 5.51$ in area 11 . A comparison of the areas under the curves in Figure $2 B$ revealed that cells in prefrontal areas 10, 11, and 12 had, on average, $\sim 3.3$ times more branches in their basal dendritic trees than do those in V1, 1.4 times more than those of cells in area $7 \mathrm{a}$, and $12-17 \%$ more than those in area TE.

\section{Basal dendritic spines}

Differences in the density of spines found on the basal dendrites of layer III pyramidal neurons in prefrontal areas, as compared with those in areas of the occipital, parietal, and temporal lobes, are illustrated in Figure 2C. Repeated measures ANOVA's confirmed that the basal dendritic fields of neurons in prefrontal areas 10,11 , and 12 were significantly more spiny than those in V1 and areas $7 \mathrm{a}$ and TE. The total number of dendritic spines in the basal dendritic arbor of the "average" layer III pyramidal neuron in each visual area was determined by combining data on the number of branches and spine density. The "average" neuron in area 10 had 8766 spines on its basal dendritic field, that in area 11 had 9786, and that in area 12 had 10,564. These values are considerably higher than those reported for V1 [(643) the average number of spines on the average layer III pyramidal neuron in the blobs and interblobs of middle and upper layer III (Elston and Rosa, 1998a)], and areas 7a (2572) and TE (7260). Thus, despite age-related effects, layer III pyramidal neurons in prefrontal areas 10,11 , and 12 have, on average, as many as 16 times more spines than neurons in V1, more than four times those in area 7a, and $45 \%$ more than those in area TE.

\section{DISCUSSION}

Pyramidal neurons in layer III were intracellularly injected in tangential cortical slices taken from cortical areas 10,11, and 12 of the macaque monkey. Comparison of their morphology with layer III pyramidal neurons in cortical areas of the occipital, parietal, and temporal lobes revealed marked differences in the cross-sectional area of, number of branches in, and spine density of the basal dendritic arbors. Moreover, there were marked differences in the estimates of the number of spines in the basal dendritic arbors of pyramidal cells in the different cortical areas.

As all cortical dendritic spines have been shown to receive at least one synapse (Colonnier, 1968; Jones, 1968; Jones and Powell, 1969), the highly spinous cells in prefrontal areas may integrate many more inputs than cells in areas such as V1, TE, and 7a. Moreover, the greater total dendritic length characteristic of prefrontal pyramidal cells may allow for a greater number of inputs (both excitatory and inhibitory) to their dendritic shafts, as compared with cells in other cortical areas such as V1, MT, and TE [for a discussion, see Elston et al. (1999b)]. The potential significance of the greater number of inputs to pyramidal neurons for their role in memory and cognition is yet to be demonstrated empirically, although fMRI studies suggest that frontal lobe function involves the integration of diverse information (Prabhakaran et al., 2000), and prefrontal cortical areas have been shown to be highly interconnected (Preuss and Goldman-Rakic, 1991b). Thus, the present findings lend further support to previous claims that an increase in the integrative ability of neurons in "higher" areas is a functional requirement for the particular type of processing performed in these areas (Elston and Rosa, 1997, 1998a,b; Elston et al., 1999a,b).

The extent of the relative differences in the number of spines in the basal dendritic arbors of pyramidal cells in cortical areas within a given animal is yet to be determined. The present data were sampled from an animal considerably older than those from which data from the other cortical areas were sampled and may have been affected by age-related spine loss (Jacobs et al., 1997). Comparison of pyramidal cells in the occipital, temporal, and frontal lobes of the same hemisphere of humans (our unpublished observations) reveal even more striking differences in cell morphology than reported here. In conjunction, these findings suggest 

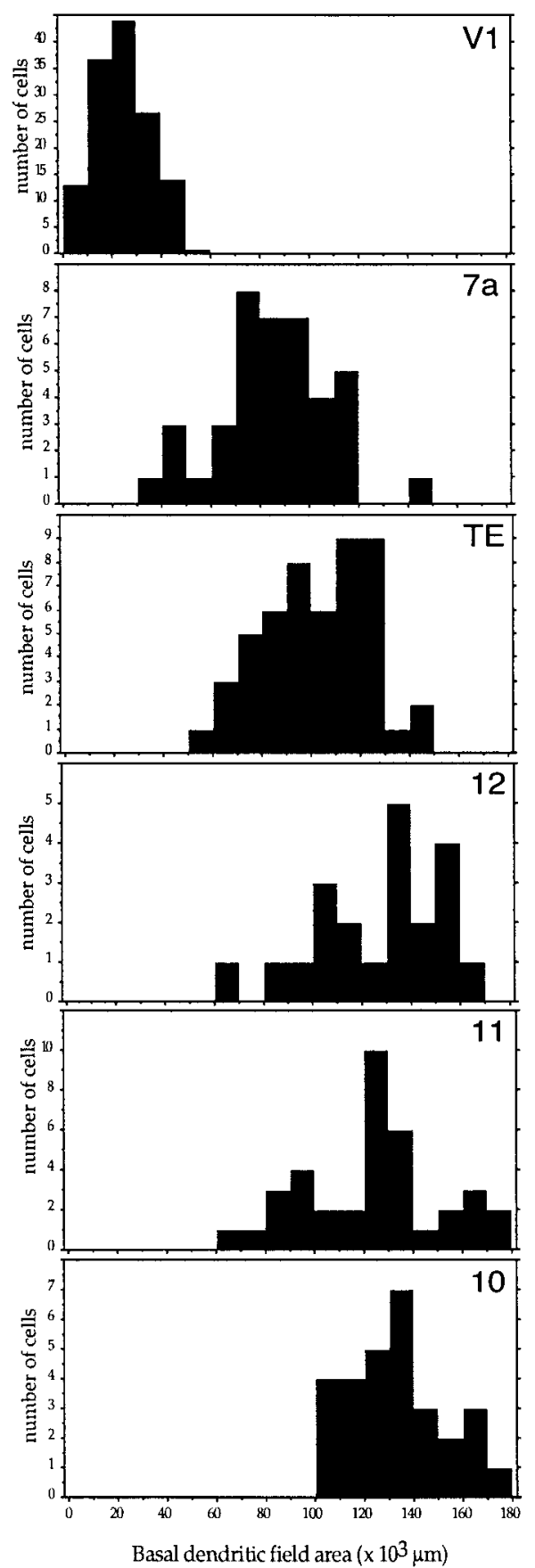
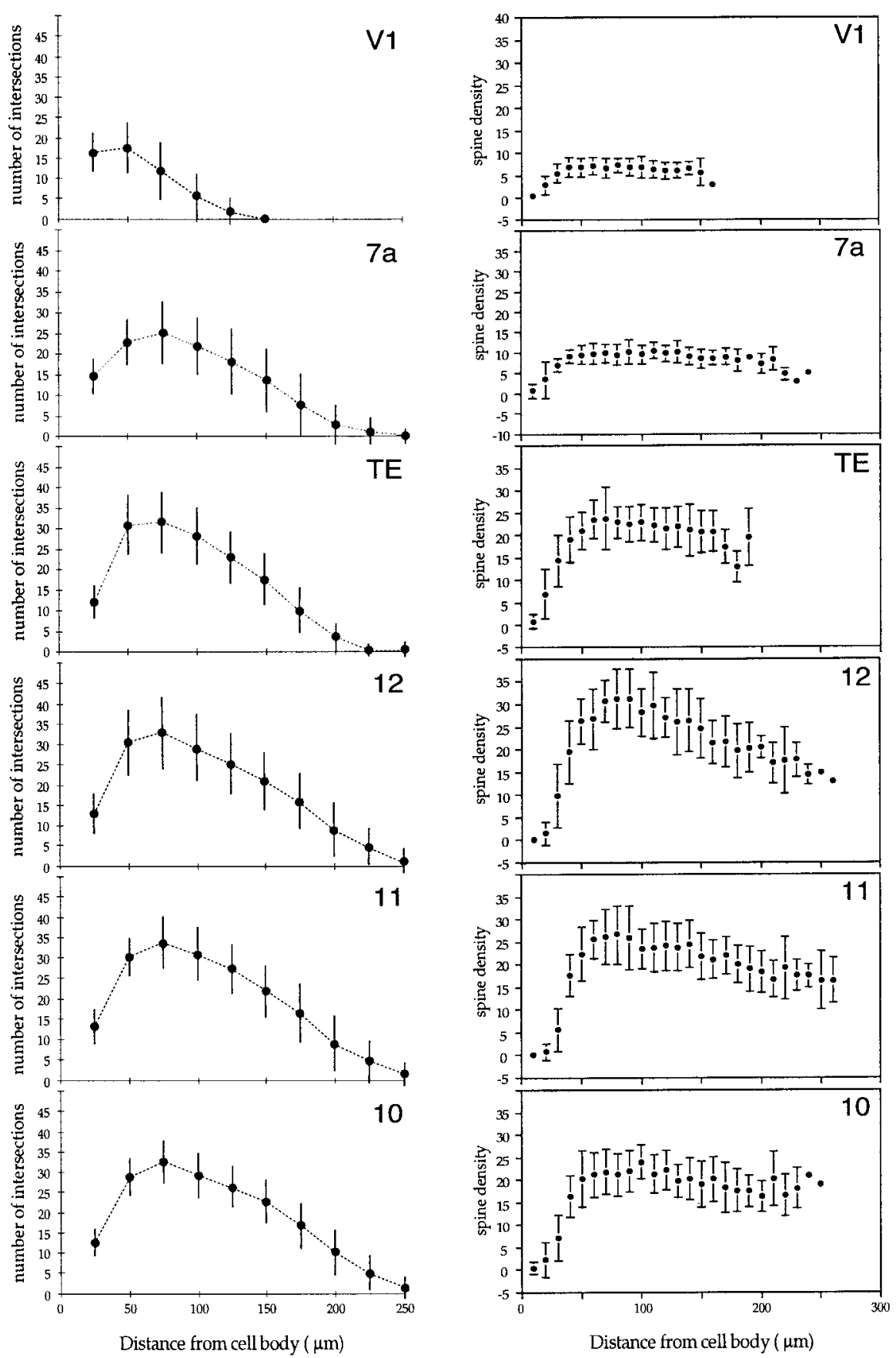

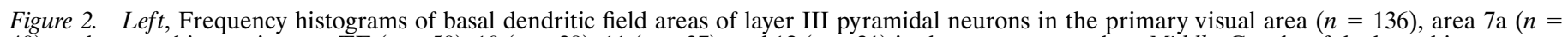

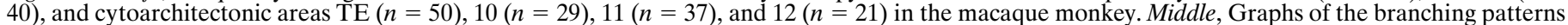

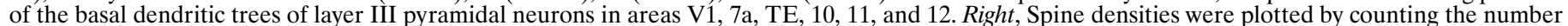

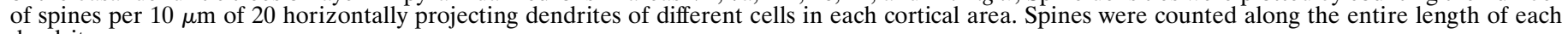
dendrite.

that the present results may be an underestimate of the relative differences in cell morphology in the macaque monkey brain.

Further developmental studies on dendritic proliferation and synaptogenesis are required in cortical areas of the parietal, temporal, and frontal lobes of macaque monkeys to determine whether the marked differences in cell morphology are determined genetically or epigenetically. Moreover, an extensive study of pyramidal cell morphology is required in prefrontal cortex to determine whether there are systematic differences in the size, branching pattern, and spine density of the basal dendritic arbors that accord with the proposed processing pathways (Wilson et al., 1993; Goldman-Rakic, 1996; Scalaidhe et al., 1997; Romanski et al., 1999), as has been demonstrated in visual cortex. It will also be interesting to determine whether pyramidal cells in limbic areas, which are also implicated in memory processes, are more or less spinous than those in prefrontal cortex.

\section{REFERENCES}

Anderson SA, Classey JD, Condé F, Lund JS, Lewis DA (1995) Synchronous development of pyramidal neuron dendritic spines and parv- 
albumin immunoreactive chandelier neuron axon terminals in layer III of monkey prefrontal cortex. Neuroscience 67:7-22.

Colonnier M (1968) Synaptic patterns on different cell types in the different laminae of the cat visual cortex. Brain Res 9:268-287.

Courtney SM, Petit L, Haxby JV, Ungerleider LG (1998) The role of prefrontal cortex in working memory: examining the contents of consciousness. Philos Trans R Soc Lond B Biol Sci 353:1819-1828.

DeFelipe J, Fariñas I (1992) The pyramidal neuron of the cerebral cortex: morphological and chemical characteristics of the synaptic inputs. Prog Neurobiol 39:563-607.

Elston GN, Rosa MGP (1997) The occipitoparietal pathway of the macaque monkey: comparison of pyramidal cell morphology in layer III of functionally related cortical visual areas. Cereb Cortex 7:432-452.

Elston GN, Rosa MGP (1998a) Morphological variation of layer III pyramidal neurones in the occipitotemporal pathway of the macaque monkey visual cortex. Cereb Cortex 8:278-294.

Elston GN, Rosa MGP (1998b) Complex dendritic fields of pyramidal cells in the frontal eye field of the macaque monkey: comparison with parietal areas 7a and LIP. NeuroReport 9:127-131.

Elston GN, Rosa MGP, Calford MB (1996) Comparison of dendritic fields of layer III pyramidal neurones in striate and extrastriate visual areas of the marmoset: a Lucifer yellow intracellular injection study. Cereb Cortex 6:807-813.

Elston GN, Tweedale R, Rosa MGP (1999a) Cortical integration in the visual system of the macaque monkey: large scale morphological differences of pyramidal neurones in the occipital, parietal and temporal lobes. Proc R Soc Lond B Biol Sci 266:1367-1374.

Elston GN, Tweedale R, Rosa MGP (1999b) Cellular heterogeneity in cerebral cortex. A study of the morphology of pyramidal neurones in visual areas of the marmoset monkey. J Comp Neurol 415:33-51.

Funahashi S, Bruce CJ, Goldman-Rakic PS (1989) Mnemonic coding of visual space in the monkey's dorsolateral prefrontal cortex. J Neurophysiol 61:331-349.

Fuster JM (1973) Unit activity in prefrontal cortex during delayedresponse performance: neuronal correlates of transient memory. J Neurophysiol 36:61-78.

Fuster JM, Alexander GE (1971) Neuron activity related to short-term memory. Science 173:652-654.

Goldman-Rakic PS (1996) The prefrontal landscape: implications for functional architecture for understanding human mentation and the central executive. Philos Trans R Soc Lond B Biol Sci 351:1445-1453.

Horner C (1993) Plasticity of the dendritic spine. Prog Neurobiol 41:281-321.

Jacobs B, Driscoll L, Schall M (1997) Life-span dendritic and spine changes in areas 10 and 18 of human cortex: a quantitative Golgi study. J Comp Neurol 386:661-680.

Jones EG (1968) An electron microscopic study of the terminations of afferent fiber systems onto the somatic sensory cortex of the cat. J Anat 103:595-597.

Jones EG, Powell TPS (1969) Morphological variations in the dendritic spines of the neocortex. J Cell Sci 5:509-529.

Kubota K, Niki H (1971) Prefrontal cortical unit activity and delayed alternation performance in monkeys. J Neurophysiol 34:337-347.

Lund JS, Yoshioka T, Levitt JB (1993) Comparison of intrinsic connectivity in different areas of macaque monkey cerebral cortex. Cereb Cortex 3:148-162.

Prabhakaran V, Narayanan K, Zhao Z, Gabrieli JDE (2000) Integration of diverse information in working memory within the frontal lobe. Nat Neurosci 3:85-90.

Preuss TM, Goldman-Rakic PS (1991a) Myelo- and cytoarchitecture of the granular frontal cortex and surrounding regions in the Strepsirhine primate Galago and the anthropoid primate Macaca. J Comp Neurol 310:429-474.

Preuss TM, Goldman-Rakic PS (1991b) Ipsilateral cortical connections of granular frontal cortex in the strepsirhine primate Galago, with comparative comments on anthropoid primates. J Comp Neurol 310:507-549.

Romanski LM, Tian B, Fritz J, Mishkin M, Goldman-Rakic PS, Rauschecker JP (1999) Dual streams of auditory afferents target multiple domains in the primate prefrontal cortex. Nat Neurosci 2:1131-1136.

Scalaidhe SP, Wilson FAW, Goldman-Rakic PS (1997) Areal segregation of face-processing neurons in prefrontal cortex. Science 278:1135-1138

Sholl DA (1953) Dendritic organization in the neurons of the visual and motor cortices of the cat. J Anat 87:387-406.

Wilson FAW, Scalaidhe SPO, Goldman-Rakic PS (1993) Dissociation of object and spatial processing domains in primate prefrontal cortex. Science 260:1955-1958. 